\title{
COMPUTER-AIDED IDENTIFICATION OF ENVIRONMENTAL IMPACTS OF BUSINESSES
}

\author{
Halina Marczak' \\ 1 Institute of Transport, Internal Combustion Engines and Ecology, Lublin University of Technology, Mechanical \\ Engineering Faculty, Nadbystrzycka 36 St., 20-618 Lublin, Poland, e-mail: h.marczak@pollub.pl
}

Received: 2015.09 .21

Accepted: 2015.10.06

Published: 2015.11.10

\begin{abstract}
Discussed elements of the computer databases used in "input-output" analysis method to identify enterprise impact on the environment. Presented "input-output" database parameters essential for a company performing road transport of finished products. Presented a method for determining parameters: energy consumption by means of road transport and the emissions amount with exhaust fumes from vehicles. Discussed parameters of the computer databases needed to calculate the amount of fees for use of the environment. These data and amount of fees for environment usage may be useful in assessing the scale of the impact on environment by businesses. Described a method for determining the fee for gases and dust emitted into the air from combustion of fuels in internal combustion engines.
\end{abstract}

Keywords: input-output, road transport, environmental impact, energy consumption.

\section{INTRODUCTION}

Companies have a large influence on the growth of the country's economic development and satisfy human needs. On the other hand, their activity may adversely affect the environment. Identification of environmental aspects in a company is the basis for the formulation of environmental objectives and tasks that allow to achieve them. Environmental aspects are the elements in business activities which affect or may affect the environment. These include resource consumption and the production of side products, such as contaminated gases, waste water and waste.

The type of environmental aspects and their impact on the environment depend on the specifics of the company. In transport companies or in companies in which one of the activities is the transport of manufactured products or other materials, environmental aspect is the consumption of energy in a form of motor fuels or emissions of nitrogen oxides. Environmental impact of these aspects are depletion of natural resources and the acidification of the air respectively.
The scope of environmental actions in companies is highly dependent on their economic situation. Worse economic condition of companies does not allow them to spend enough financial resources for environmental purposes. Avoiding increased costs for environment protection may also be related to strong competition on the market. Businesses believe that the effects of rising expenditures on environmental protection will increase the prices of products and services, and this in turn will reduce their competitiveness and cause a loss of their market position.

Actual legal regulations are important for environment protection in businesses. The need to comply with legal requirements mobilizes companies to pursue protective investment and spending money on environment protection.

Planning measures to eliminate or minimize pressure on the environment of companies should be preceded by identifying environmental aspects and problems and the needs in the field of environmental protection in companies.

A tool for identifying the environmental aspects of a business can be a method of ,input-output" analysis. It involves the creation of relevant 
databases, preferably computer ones. The next step is the analysis of the data focused on defining the elements of company's activities that cause environmental problems and require changes in order to minimize their negative impact on the environment.

The research objective of the article is to present theoretical data sets collected in computerized databases as tools to help identifying the environmental impacts of a company engaged in road transport of goods.

\section{INPUT-OUTPUT ANALYSIS FOR A ROAD TRANSPORT COMPANY}

A tool that determines the elements of business activities (environmental aspects) that may cause impact on the environment and the extent of this impact is the method of „,input-output analysis". It involves determining the inputs of an activity involving a kind of consumed natural resources, energy and other substances, and also outputs, which include the effects of activities in a form of finished products, services and by-products. The elements of input and output activities in the road transport of finished goods are presented in Figure 1.

Another step is to create sets of figures related to the established input and output elements. The „input - output" datasets should be collected and analysed systematically for a considered time interval, e.g. a month or a quarter. The execution, based on the collected data, calculations, analyses and reports will be much easier with computer databases. It is advised to create the following computer databases:

- a database of „input-energy” concerning energy consumption,
- a database of ,input materials and products” containing information relating to the consumption of raw materials other than energy and materials necessary to conduct a business,

- a database of „output-products” containing information about quantity of produced basic products and by-products; the base necessary for production,

- a database of ,output-other effects” about the effects of non-production activities; the base needed for service companies or companies whose one of activities is transportation of finished products,

- database „output-material by-products” containing information about the amount of byproduct, such as waste, waste water, gaseous pollutants, dust, other substances,

- database „output-non-material by-products" about the amount of the energy emitted, e.g. noise, vibrations, waste heat, electromagnetic radiation.

A list of ,input-output" parameters of databases which are essential for a company engaged in road transport of goods is shown in Figure 2.

Numerical value of energy consumption in road transport can be determined according to the relationship:

$$
Z_{e}=Z_{p a l} \cdot W E_{p a l}
$$

where: $Z_{e}$ - energy gained from burning motor fuel, MJ;

$Z_{p a l}-$ motor fuel consumption during the assessed period, in $\mathrm{dm}^{3}$ (for liquid fuel) or $\mathrm{m}_{\mathrm{n}}{ }^{3}$ (for gas);

$W E_{p a l}$ - the energy value of the fuel in $\mathrm{MJ} /$ $\mathrm{dm}^{3}$ (for liquid fuel) or in $\mathrm{MJ} / \mathrm{m}_{\mathrm{n}}^{3}$ (for gas).

Energy values of motor fuels are given in the regulation on non-price evaluation criteria man-

Transport performance

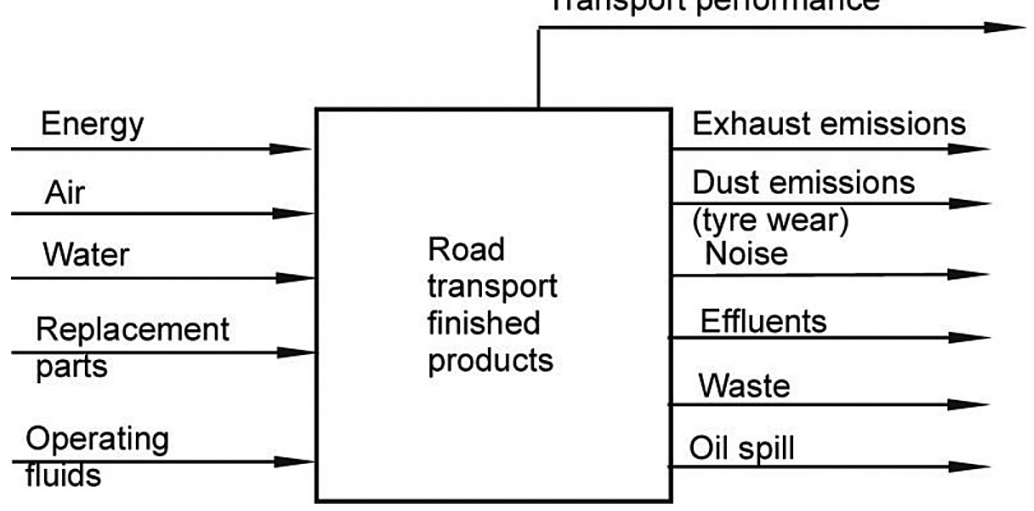

Figure 1. Input and output elements in the road transport of goods 
datory for certain types of public procurement [5]. When assessing the impacts of a company on the environment one should take into account the share of biofuels in overall consumption of motor fuels. This parameter should be a component of the database ,input-energy”. Furthermore, this database should contain data on energy consumption from the power grid. The decrease in electricity consumption from the grid will be undoubtedly influenced by the use of energy saving bulbs in company's venues.

The result (environmental impact) of the consumption of petroleum transportation fuels is the reduction of non-renewable natural energy resources. The extent of the environmental impact in this area is indicated by the amount of fuel consumption.

The data in the database ,input - raw materials" include the amount of consumed surface water, underground water, including water supplied from the network, water for consumption, sanitary water and water used for washing vehicles if the company has a truck wash, the number of spare parts (components) and fluids and other consumables divided into those that can be renewed and recycling and the other, the number of tires purchased with indication of their quality, for example tires with lower rolling resistance.
In the output data an important place is occupied by the information on the effects of the activities. The effect of operations in the transport of finished products is the amount of transported goods.

Environment will be influenced by such activities of a transporting company as emissions from exhaust gas components: nitrogen oxides $\left(\mathrm{NO}_{\mathrm{x}}\right)$, carbon monoxide $(\mathrm{CO})$, sulphur dioxide $\left(\mathrm{SO}_{2}\right)$, hydrocarbons $(\mathrm{HC})$ and carbon dioxide $\left(\mathrm{CO}_{2}\right)$ emissions of PM10 dust, emitted into surface water or soil or sewage system, waste water containing organic materials (petroleum, detergents), production of solid and liquid waste, noise emission, waste heat from the exhaust and events accompanied by spilling fluids or property damage. The quantitative data in this area should be contained in databases „output - material byproducts” and ,output - non-material by-products" respectively.

Emissions of $\mathrm{NO}_{x}, \mathrm{CO}, \mathrm{HC}, \mathrm{PM} 10$ from exhaust gases from a vehicle type can be defined with the formula:

$$
E_{i}=p \cdot W_{e i}
$$

where: $i$ - the type of exhaust component

$$
\begin{aligned}
& E_{i}-\text { emission component } i, \mathrm{~g} \\
& p-\text { mileage, } \mathrm{km} \\
& W_{e i} \text { - indicator component of } i \text { element } \mathrm{g} / \mathrm{km} .
\end{aligned}
$$

\begin{tabular}{|c|c|}
\hline Input & Output \\
\hline $\begin{array}{l}\text { A. Energy } \\
\text { A1. Obtained from combustion process: } \\
\text { - solid fuels } \\
\text { - liquid fuels } \\
\text { - gaseous fuels } \\
\text { A2. From the energetic grid }\end{array}$ & $\begin{array}{l}\text { A. Effects of activities: } \\
\text { - road transportation }\end{array}$ \\
\hline $\begin{array}{l}\text { B. Raw materials and consumables: } \\
\text { - spare parts (components) } \\
\text { - fluids and consumables } \\
\text { - underground water from water systems } \\
\text { - water from groundwater sources } \\
\text { - surface water }\end{array}$ & $\begin{array}{l}\text { B. Material by-products: } \\
\text { - gaseous exhaust components } \\
\text { - particulates in the exhaust } \\
\text { - dust from the abrasion of tires } \\
\text { - total sewage } \\
\text { - sewage discharged to the sewerage network } \\
\text { - sewage discharged to receivers } \\
\text { - total waste } \\
\text { - hazardous waste and other } \\
\text { - waste recovered in the company } \\
\text { - waste transferred for recovery, including recycling } \\
\text { - waste disposed of in a company } \\
\text { - waste for disposal }\end{array}$ \\
\hline & $\begin{array}{l}\text { C. Non-material by-products: } \\
\text { - noise, vibration } \\
\text { - waste heat }\end{array}$ \\
\hline
\end{tabular}

Table 1. „Input-output” parameters of databases essential for a road transport company 
The value of $W_{e i}$ emission of exhaust components $\mathrm{NO}_{x}, \mathrm{CO}, \mathrm{HC}, \mathrm{PM} 10$ may be adopted in accordance with the COPERT 4 method [1], which allows to take into account the average speed on a particular type of road infrastructure (town, city, highway) type of vehicle (e.g. car, light and heavy truck, characterized by the following parameters: fuel type, engine capacity of passenger vehicles, gross vehicle weight rating of heavy utility vehicles, emission standard Euro $[2,6]$.

$\mathrm{CO}_{2}$ emissions depend on the amount of burnt fuel and can be estimated using the relationship:

$$
E_{\mathrm{CO}_{2}}=\frac{44}{12} \frac{U_{C}}{100} \rho_{p a l} Z_{p a l}
$$

where: $E_{\mathrm{CO}_{2}}-\mathrm{CO}_{2}$ emissions, $\mathrm{g}$

$44 / 12$ - conversion from the reaction of carbon oxidation, which indicates that $1 \mathrm{~g}$ of carbon (C) gives 44/12 $\mathrm{g} \mathrm{CO}_{2}$

$U_{c}$ - the share of coal in the fuel, $\%(\mathrm{~m} / \mathrm{m})$

$\rho_{\text {pal }}-$ density of the fuel, $\mathrm{g} / \mathrm{dm}^{3}$

$Z_{p a l}$ - fuel consumption, $\mathrm{dm}^{3}$.

Between the size of $\mathrm{SO}_{2}$ emissions and fuel consumption there is a relationship, thus this parameter can be estimated on the basis of fuel consumption using the formula:

$$
E_{\mathrm{SO}_{2}}=2 S \cdot \rho_{p a l} \cdot Z_{p a l} \cdot 10^{-6}
$$

where: $E_{\mathrm{SO}_{2}}$ - emissions of $\mathrm{SO}_{2}, \mathrm{~g}$

$S$ - sulphur content in the fuel, $\mathrm{ppm}(\mathrm{m} / \mathrm{m})$

$\rho_{p a l}, Z_{p a l}-$ as in formula (3).

The evaluation of environmental impact of waste water discharged by the company is possible on the basis of data on the amount of used water discharged to the sewage treatment plants and entering the sewage system, as well as the values of parameters characterizing the wastewater composition, particularly the concentration of oil substances, concentrations of suspensions, the indicators $\mathrm{BOD}_{5}$ (five-day, biochemical oxygen demand), COD (chemical oxygen demand), the sum of chlorides and sulphates. These parameters should be monitored regularly and recorded in the database „output-material by-products”.

An important element of the database „output-material by-products" is the data on the types of waste and their codes according to the Catalogue of waste [7], the amount of waste and method of their management with consideration to the amount of waste to be recovered or disposed of by the company alone or through specialized companies.

\section{DATA FOR THE DETERMINATION OF FEES FOR THE USE OF THE ENVIRONMENT}

The effect of environmental actions in a company, which particularly prevent pollution, in addition to a reduction in business pressures on the environment should also be measurable economic benefits in a form of lower fees for using the environment (environmental fees). Lower fees for using the environment indicate a smaller scale impacts of business on the environment.

The fees are a component of the running costs of ecological environment. Apart from them, running costs include the costs of ,end of pipe" operations, i.e. eliminating the production of impurities (e.g. sewage treatment plants, landfills), the operating costs of actions to prevent pollution (running costs may include only incremental costs compared to the costs of the alternative technology operating without actions for environment protection), service charges, research and development costs and monitoring costs.

Companies involved in the transport of finished products are certainly subjects to the fee for gases and dust emitted from combustion of fuels in internal combustion engines. The amount of the fee per year is determined by the formula:

$$
Q_{s p}=Z_{p a l} \cdot s
$$

where: $Q_{s p}-$ fee for gases and dust emitted, PLN $Z_{p a l}$ - fuel consumption in the period, $\mathrm{Mg}$ $s-$ unit fees PLN/Mg.

The unit fee rate depends on the type of fuel used, permissible gross vehicle weight and the date of first registration, or from the EURO emission standards met by the vehicle. The rates are determined by the Regulation on fees for using the environment [3]. The mass of a given volume of fuel should be determined using fuel density: $0.755 \mathrm{~kg} / \mathrm{dm}^{3}$ for motor gasoline, $0.84 \mathrm{~kg} / \mathrm{dm}^{3}$ for diesel and biodiesel, $0.5 \mathrm{~kg} / \mathrm{dm}^{3}$ for liquid gas propane-butane (LPG), $0.74 \mathrm{~kg} / \mathrm{m}^{3}$ for compressed natural gas $(\mathrm{CNG})$.

Companies with other sources of toxic gas and dust emission into the air, like burning fossil sources of energy (furnace, boilers), fuel combustion in other than power generation installations, technological processes (varnishing, welding, painting), the transhipment of motor gasoline, have an obligation to calculate the fee for gases and dust emitted into the air from these sources.

In case the company takes all of the water from the water supply system and the sewage is 
discharged into the municipal sewerage system, then such a way of wastewater management is not subject to environmental charges. The company is charged by water provider and wastewater recipient only. While the fee for the use of the environment is charged in case groundwater, surface water, inland and coastal waters are used for business purposes.

The fee for using surface waters is calculated from the formula:

$$
O_{w p}=V \cdot s \cdot w
$$

where: $O_{w p}$ - fee for groundwater extraction, PLN $V$ - the amount of underground water used, $\mathrm{m}^{3}$

$s$ - unit rate charge for underground water intake, PLN $/ \mathrm{m}^{3}$

$w-\mathrm{a}$ fee differentiating factor.

Unit rate fee for using groundwater depends on the purpose. There are, three types of purposes: consumption, social and living, and production and for other purposes.

The value of the fee differentiating factor depends on the quality of water and water treatment methods performed by the user. For example, if water is not subject to treatment processes or it is only disinfected or demineralized, the factor $w=2$. In case where water is subjected to ammonia removal, coagulation, or adsorption, the factor $w=0.5$.

Individual fees for $1 \mathrm{~m}^{3}$ of groundwater and differentiating factors are given in the regulation on the fees for using the environment [3].

Database on charges for groundwater use should include the following information: the quantity of water used in the reporting period, the code corresponding to the purpose of using water, water quality indicators, unit fee rates, the factors differentiating the fee.

Discharging rainwater or snowmelt collected in a closed or open sewage systems, except an ordinary sewage system, into surface water or ground water treatment is also subject to fees. Transport companies supplying waste water from washing vehicles to the sewage system are subject to this fee. The fee for releasing waste into surface waters or surface waters are determined according to the formula:

$$
O_{\dot{s}}=\max O_{\dot{s} 1 i}+\sum_{j} O_{\dot{s} 2 j}
$$

where: $O_{\dot{s}}-$ fee for releasing waste into surface waters or soil, PLN $\max O_{s 1 \mathrm{i}}-$ the value of highest fee calcu- lated separately for contamination and expressed by $i$ factors; the following indicators are taken into account: $\mathrm{BOD}_{5}, \mathrm{COD}$ (chemical oxygen demand determined by dichromate method), total suspended solids, total chloride and sulphate ions, PLN $O_{j 2 j}-$ fees for other substances, such as volatile phenols, heavy metals and other substances listed in the Regulation on fees for using the environment [3], PLN $j$-type substances covered by the fee.

The fee for contamination expressed by $i$ indicator is calculated for each indicator, according to the formula:

$$
O_{\dot{s} 1 i}=t_{i} \cdot s \cdot w
$$

where: $t_{i}=S_{i} \cdot Q_{\dot{s}}$

$E_{i}$ - pollutant load expressed by $i$ indicator, $\mathrm{kg}$

$S_{i}$ - impurity concentration expressed by $i$ indicator, $\mathrm{g} / \mathrm{dm}^{3}$

$Q_{\dot{s}}-$ the amount of wastewater, $\mathrm{m}^{3}$

$s$ - unit fee rate (according to [3]) per 1

$\mathrm{kg}$ of substances released into the sewage system or to the ground, PLN $/ \mathrm{kg}$

$w$ - a factor differentiating the fee for $\mathrm{BOD}_{5}$ and COD depending on the type of wastewater (taken according to [4]), for other pollutants the coefficient $w=1$.

$O_{j 2 j}$ fee for other substances in industrial or municipal wastewater, other water for living purposes, is calculated according to the formula:

$$
O_{s 2 j}=t_{j} \cdot s
$$

where: $t_{j}-$ load of $j$ substance covered by the fee, $\mathrm{kg}$ $s$ - unit fee rate (according to [3]) for 1 $\mathrm{kg}$ of substances released into the sewage system or to the ground, PLN/kg.

The database of information necessary to determine the fees for releasing sewage into surface waters or soil should contain the following parameters: the amount of sewage, the type of sewage, concentration of substances in the wastewater taken into account when calculating the fee, the unit rate of charge and the values of fee differentiating factor.

In the case where the company has its own rainwater water drainage system collecting contaminated rainwater and snowmelt flowing down from the surface of the owned permanent surfaces and discharges the water into the sewage system, the company is required to determine the fees for 
using the environment. The fee for the billing period ( 1 year) is determined by the formula:

$$
Q_{s_{s} o p}=P \cdot S
$$

where: $Q_{\dot{s} \text { op }}-$ fee for rainwater and snowmelt discharged into surface water or soil, PLN $P$ - the area from which rainwater and snowmelt are collected, $\mathrm{m}^{2}$ $s-$ unit fee rate (according to [3]) per 1 $\mathrm{m}^{2}, \mathrm{PLN} / \mathrm{m}^{2}$

\section{CONCLUSIONS}

Most companies have a passive strategy of actions towards the environment. It involves the implementation of solutions that allows only for complying with the requirements of environment protection. Some companies are committed to set higher environmental goals, expressing high environmental awareness and responsibility. Taking a wider range of pro-environmental actions is related to the intention to implement a formal environmental management system according to ISO 14001 or EMAS regulation (Eco-Management and Audit Scheme), with the desire to improve the image to customers and investors and achieve higher competitiveness.

The basis for defining the objectives and tasks in the field of environmental protection and the program of their implementation is identifying and constantly updating the environmental aspects, i.e. those elements of the company's activities which have or may have an impact on the environment.

A tool that supports identification of environmental aspects of the company and their impact on the environment is a method of ,input-output" analysis. A good solution is to create digital databases. The data included in ,input-output” data- bases should be systematically collected and analysed at predetermined intervals. Current analysis of this data allows for identification of the elements of business activities that cause environmental problems and need to be changed.

The effect of environmental actions in a company, in particular those that prevent pollution, not only reduce company's pressures on the environment, but also give measurable economic benefits in a form of lower fees for using the environment.

Lower fees for using the environment indicate a smaller scale of company's impact on the environment. The figures of fees for the use of the environment collected in computer databases may be useful in assessing the scale of the of company's impact on the environment.

\section{REFRENCES}

1. COPERT 4 - Estimating emissions from road transport. European Environment Agency, www. emisia.com/copert

2. Marczak H. 2015. The costs of energy and pollution generated by road transporation vehicles. Logistyka, no. 3.

3. Information on the fees for using the environment. MP 2014, item 790.

4. Regulation on the fees for using the environment. Dz.U. 2008 no. 196, item 1217.

5. Regulation on non-price evaluation criteria mandatory for certain types of public procurement. Dz.U. 2011 no. 96, item 559.

6. Trela M. 2012. Economic instruments of external cost internationalisation of road transporation in Poland. Doctoral dissertation, AGH Cracow.

7. Regulation of the ministry of environment on the catalogue of waste. Dz.U. 2014, item 1923. 